\title{
Decolourisation and detoxification of CI Direct Blue 201 textile dye by two fungal strains of genus Aspergillus
}

\author{
EMMS Ekanayake ${ }^{1,2}$ and PM Manage ${ }^{1^{*}}$ \\ ${ }^{1}$ Centre for Water Quality and Algae Research, Department of Zoology, University of Sri Jayewardenepura, Gangodawila, Nugegoda. \\ ${ }^{2}$ Faculty of Graduate Studies, University of Sri Jayewardenepura, Gangodawila, Nugegoda.
}

\begin{abstract}
Two fungal strains capable of decolourisation of CI Direct Blue 201 textile dye were isolated from textile wastewater effluent sites in Sri Lanka and they were identified as Aspergillus aculeatus and Aspergillus nomius using 18s rRNA analysis. A. nomius and A. aculeatus showed $98 \%$ decolourisation of CI Direct Blue 201 textile dye $(50 \mathrm{mg} / \mathrm{L})$ at $3^{\text {rd }}$ day of incubation with the supplement of modified Kirk's medium. Both fungal strains were found to be more effective for dye decolourisation at temperatures ranging from $24{ }^{\circ} \mathrm{C}$ to $36{ }^{\circ} \mathrm{C}$. Further, it was found that the decolourisation potential increased at $\mathrm{pH} 5$ and 10 under shaking condition (100 rpm) with the presence of glucose and nitrate as additional carbon and nitrogen sources. Seed germination assay showed less germination $(22.2 \pm 5.0 \%$ and $10.0 \pm 3.3 \%$ for Oryza sativa and Vigna radiata, respectively) when seeds were exposed to the original dye in comparison to $100 \%$ seed germination observed when exposed to fungal treated dye effluent, showing the detoxification of dye by the fungal isolates.
\end{abstract}

Keywords: Aspergillus aculeatus, Aspergillus nomius, bioremediation, CI Direct Blue 201 textile dye, decolourisation.

\section{INTRODUCTION}

The use of synthetic dyes has been increasing gradually and a significant part of these finds its way into the environment in several forms and quantities (Anjana $\&$ Thanga, 2011). Textile based industries account for the majority of the coloured waste effluent water and approximately $50 \%$ from their original dye bath is released due to the low level of dye fibre fixation rate
(Bumpus, 1995; Kalyani et al., 2008). Therefore, around 280,000 tons of textile dyes are discharged into the environment annually worldwide and adversely account for water and soil pollution (Jin et al., 2007).

Generally, around 10,000 different dyes are used in textile industries in the world (Chen et al., 2003). Among these, azo dyes are the major group which are extensively used in the textile industry and account for approximately $70 \%$ of the world synthetic dye production by weight (Chen et al., 2003). It has been documented that the complex aromatic structural nature of these dyes show resistance to the natural oxidation processes and therefore, the dyes persist in surface water and sediments for a long time (Przystas et al., 2015). Recent studies have revealed that improper wastewater disposal into natural waterways causes a collapse of ecosystems resulting mainly in the reduction of light penetration in aquatic systems. Further, textile dyes adversely affect the health of aquatic flora and fauna as most of the synthetic dyes are toxic, carcinogenic and mutagenic (Banat et al., 1996). Thus, removal of synthetic dyes from textile dye wastewater effluent is vital for long-term ecological balance as well as for environmental health and integrity.

Currently, various physical and chemical treatment methods such as adsorption (Morais et al., 1999), coagulation (Roussy et al., 2005), flocculation (Roussy et al., 2005) and ion exchange (Robinson et al., 2001) are practiced worldwide. Biological treatment methods

\footnotetext{
* Corresponding author (pathmalal@sjp.ac.lk; (DD https://orcid.org/0000-0002-2014-2060)
} 
(Pandey et al., 2007; Kalyani et al., 2008) show an increasing trend in utilisation as eco-friendly and lowcost alternatives to the costly and inefficient physical and chemical methods mentioned above (Robinson et al., 2001). There are a limited number of scientific reports on the bioremediation of textile dyes using bacteria (Kalyani et al., 2008; Ekanayake \& Manage, 2017), fungi (Bankole et al., 2018), algae (Anandhana et al., 2018) and aquatic plants (Anjana \& Thanga, 2011). Among the various types of biological agents, fungi produce a high biomass yield with a lesser amount of nutrients (Kabbout \& Taha, 2014 ) and recent studies have revealed that most of the fungal strains depend on inexpensive media to produce an extensive amount of hyphae making them more effective in dye decolourisation applications (Kabbout \& Taha, 2014). Therefore, recent research aims at discovering new fungal strains that are able to decolourise textile wastewater effluents effectively.

According to recent scientific reports some fungal strains; Peyronellaea prosopidis (Bankole et al., 2018), and Aspergillus niger (Rani et al., 2014) have the ability to decolourise different textile dyes such as Basic fuchsin, Nigrosin, Malachite green, Congo red, Red RBL and Scarlet GDR efficiently. According to our knowledge, no research has been carried out for fungal remediation of textile dyes in Sri Lanka, although textile wastewater is rated as the second major polluter in Sri Lanka following natural rubber industry (CEA, 1992). Although a few textile industries treat the effluent prior to discharge, many industries discharge effluents directly to the nearest surface water bodies such as the Kelani river, Bolgoda lake and Lunawa lagoon in Sri Lanka (CEA, 1992; Ileperuma, 2000; Mahagamage et al., 2015; Mahagamage \& Manage, 2015). Disposal of these effluents in concentrated forms create negative impacts on surface and ground water (Ileperuma, 2000; Mahagamage et al., 2015; Mahagamage \& Manage, 2015). Moreover, being a niche supplier of high quality apparel to the world and providing a wide range of direct and indirect job opportunities, the Central Bank of Sri Lanka highlights the necessity of discovering new dimensions and capacities of textile and textile processing industries in Sri Lanka (Central Bank of Sri Lanka, 2016). Treatment of textile wastewater effluent is essential to maintain the discharge quality standards. Thus, the present study aimed at isolation and characterisation of textile dye decolourising and detoxifying fungal strains from textile wastewater effluent sites in Sri Lanka as a green solution to strengthen the textile industry without causing pollution.

\section{METHODOLOGY}

\section{Chemicals and dyes}

CI Direct Blue 201 textile dye was selected as the model dye for the study and was obtained from the local textile industry. The $\mathrm{pH}$ of the dye was 8.1.

\section{Sample collection}

Water and soil samples were collected into sterilised glass bottles and polythene bags, respectively from textile wastewater effluent sites; Biyagama $\left(6^{0} 57^{\prime} 28.85^{\prime} \mathrm{N}\right.$, $\left.79^{0} 59^{\prime} 41.21^{\prime \prime} \mathrm{E}\right)$ and Pugoda $\left(6^{0} 58^{\prime} 58.02^{\prime} \mathrm{N}, 80^{\circ} 07^{\prime}\right.$ 23.86"E) in Sri Lanka and three samples were collected from each location. General water quality parameters, temperature, $\mathrm{pH}$, dissolved oxygen (DO) and electric conductivity (EC) were measured at the site using standard digital meters (pH 3110, DO 3110, Cond 3110 and WTW GmbH, Weilheim, Germany, respectively). Collected water and soil samples were stored in cool boxes at $4{ }^{\circ} \mathrm{C}$ and transported to the laboratory within $4 \mathrm{~h}$. Water hardness, phosphate, biological oxygen demand (BOD), total dissolved solids (TDS), total suspended solids (TSS), nitrate nitrogen $\left(\mathrm{N}^{-\mathrm{NO}_{3}}{ }^{-}\right)$and ammonium nitrogen $\left(\mathrm{N}^{-\mathrm{NH}_{4}}{ }^{+}\right)$were analysed using the standard methods (APHA, 1995).

\section{Isolation and molecular identification of the fungus}

Water samples $(1.0 \mathrm{~mL})$ and soil samples $(1.0 \mathrm{~g})$ were enriched with $50 \mathrm{mg} / \mathrm{L}$ of CI Direct Blue 201 textile dye respectively in a shaking incubator at $100 \mathrm{rpm}\left(28^{\circ} \mathrm{C}\right)$ for a period of 14 days. The antibiotic tetracycline was added to the Potato Dextrose Agar (PDA) medium (in $\mathrm{g} / \mathrm{L}$; dextrose: 20, yeast extract: 5 , potato infusion: 200 and agar 15 ) at $0.1 \mathrm{mg} / \mathrm{L}$ of final concentration (Plácido et al., 2016) and spread plate method was performed to isolate fungi. After seven days of incubation, fungi showing different morphological features were isolated and pure cultures were prepared after several repeated streaking. The isolated fungal strains were maintained on PDA slants, which were spiked with CI Direct Blue 201 textile dye as an additional carbon source (final concentration of $10 \mathrm{mg} / \mathrm{L}$ ) and slants were stored at $4{ }^{\circ} \mathrm{C}$.

\section{Decolourisation of textile dye by fungi}

Decolourisation experiment was carried out in two phases. Firstly, solid medium screening was performed to primarily identify the effective textile dye decolourising 
fungal candidates. Secondly, decolourisation ability of the selected potential fungal candidates was qualitatively evaluated using liquid medium decolourisation experiment (Plácido et al., 2016).

In solid medium screening, one disc $(5 \mathrm{~mm}$ diameter) of fungal mycelium was cut from the edge of a pre-grown 5 days old fungal culture plate and placed on the centre of a petridish containing $15 \mathrm{~mL}$ of PDA overlaid with $5 \mathrm{~mL}$ of PDA with $0.01 \%(\mathrm{w} / \mathrm{v})$ CI Direct Blue 201 textile dye (Rani et al., 2014). Plates were incubated for 7 days at $28{ }^{\circ} \mathrm{C}$. The plates with un-inoculated PDA overlaid with $0.01 \%$ dye were maintained as the control. Two trials were carried out for all the experiments and in each trial, triplicate samples were maintained. Effective fungal isolates were selected by observing clear zones of the overlaid dye coat and isolates were classified as a positive agent for decolourisation when the media exhibited partial or total clear zones on agar plates when compared with the control plates. Decolourisation was defined when decolourisation zones were; $>5 \mathrm{~cm}-$ High, $5-2 \mathrm{~cm}=$ Medium, $<2 \mathrm{~cm}-$ Low (Rani et al., 2014). Potential fungal candidates were subjected to liquid medium screening. The effective fungal isolates were identified by $18 \mathrm{~s}$ rRNA analysis by Genetech (Pvt.) Ltd., Sri Lanka.

In the liquid medium, CI Direct Blue 201 textile dye was added to $50 \mathrm{~mL}$ of autoclaved modified Kirk's medium in $\mathrm{g} / \mathrm{L}$; Glucose: $2, \mathrm{KH}_{2} \mathrm{PO}_{4}: 0.20, \mathrm{MgSO}_{4} .7 \mathrm{H}_{2} \mathrm{O}$ : $0.05, \mathrm{CaCl}_{2}: 0.01, \mathrm{CuSO}_{4} \cdot 7 \mathrm{H}_{2} \mathrm{O}: 0.08, \mathrm{MnSO}_{4}: 0.05$, $\mathrm{ZnSO}_{4} \cdot 7 \mathrm{H}_{2} \mathrm{O}: 0.033, \mathrm{Fe}\left(\mathrm{SO}_{4}\right)_{3}: 0.05$ (Plácido et al., 2016) to obtain $50 \mathrm{mg} / \mathrm{L}$ of final dye concentration and final $\mathrm{pH}$ was maintained at 7 . Four discs $(5 \mathrm{~mm}$ diameter) of fungal mycelium were inoculated into each flask and incubated at $28{ }^{\circ} \mathrm{C}$ under shaking at $100 \mathrm{rpm}$ for 7 days. All the experiments were carried out in triplicates and control was maintained under the same conditions without the addition of fungal inoculants. At $24 \mathrm{~h}$ intervals, $3 \mathrm{~mL}$ aliquot of the culture supernatant was withdrawn, centrifuged and colour reduction was monitored by measuring the changes of absorbance using UV-VIS spectrophotometer (Labomed, Inc., USA). Maximum wavelength ( $\lambda$ max) for CI Direct Blue 201 textile dye was considered as $570 \mathrm{~nm}$, which was previously determined by Ekanayake and Manage (2017). Decolourisation percentage (DP) was determined by following the equation given by Gupta et al. (2016), where $\mathrm{C}_{0}$ and $\mathrm{C}_{1}$ denote initial dye concentration and final dye concentration, respectively.

$\operatorname{DP}(\%)=\left[\left(\mathrm{C}_{0}-\mathrm{C}_{1}\right) / \mathrm{C}_{0}\right] 100$
Optimisation of temperature, $\mathrm{pH}$, initial dye concentration, shaking and static conditions and the nutrient condition of fungal isolates for the decolourisation of CI Direct Blue 201 textile dye

Decolourisation of CI Direct Blue 201 textile dye was optimised for $\mathrm{pH}(5,6,7,8,9$ and 10), temperature (24, 28,32 and $\left.36{ }^{\circ} \mathrm{C}\right)$, initial dye concentration $(25,50,75$, $100,150,200 \mathrm{mg} / \mathrm{L})$, shaking (50, 100 and $150 \mathrm{rpm}$ ), static condition, nitrogen (ammonium nitrate, ammonium chloride) and carbon (glucose, starch) in the medium to determine the effectiveness of the above factors on dye decolourisation by fungal isolates. The decolourisation experiment was carried out by changing each parameter in the modified Kirk's medium following the same procedure described under decolourisation of textile dye by fungi. The basal medium was further supplemented by adding $1 \%(\mathrm{w} / \mathrm{v})$ of ammonium nitrate, ammonium chloride, glucose or starch when the effect of nutrients was evaluated. All the experiments were carried out in triplicates and control was maintained without fungal inoculant. Fed-batch process was followed by adding $50 \mathrm{mg} / \mathrm{L}$ textile dye at the end of each cycle to assess the repetitive decolourisation capacity of the selected isolates.

\section{Biosorption assay}

For biosorption test, 5-day-old live and autoclaved $(5 \pm 0.5 \mathrm{~cm}$ diameter) fungal cultures were introduced into $50 \mathrm{~mL}$ of CI direct Blue 201 textile dye at a final concentration of $50 \mathrm{mg} / \mathrm{L}$ and incubated under shaking at $100 \mathrm{rpm}$ for 7 days at $28^{\circ} \mathrm{C}$. Control was maintained without addition of fungi. Colour removal percentage was calculated by following the method described under decolourisation of textile dye by fungi.

\section{Toxicity assay}

The toxic effect of the decolourised dye solution was determined through seed germination assay with the monocot Oryza sativa and dicot Vigna radiata to find whether the fungi treated textile dye affect regular plant physiological processes (Kalyani et al., 2008). Thirty seeds from each species were placed on wet tissue overlaid petridishes and incubated while spraying $5 \mathrm{~mL}$ of $50 \mathrm{mg} / \mathrm{L}$ dye and decolourised effluent water of fungal treatment, daily. Control was maintained by moistening the seeds with autoclaved distilled water under the same condition. Two trials were carried out in triplicates. Seed germination percentages were recorded after 5 days (Kalyani et al., 2008) in both the control and the treatment. 


\section{RESULTS AND DISCUSSION}

CI Direct Blue 201 textile dye $(834 \mathrm{~g} / \mathrm{mol})$ has a complex chemical structure, having two azo bonds and three sulfur groups on seven aromatic rings (Figure 1) (Chemical Book, 2017). This dye is extensively used in Sri Lanka for cotton, silk and viscose textile industry. The presence of azo and sulfo groups on the aromatic components are highly recalcitrant to natural decolourising processes (Kulla et al., 1983). Thus, due to the chemical nature of CI Direct blue 201 textile dye, it significantly inhibits the decolourising efficiency of most biological agents.

In the present study, water and soil samples were collected from textile wastewater effluent sites where regular exposure to heavy loads of textile wastewater was recorded (Mahagamage et al., 2015). General water quality parameters of wastewater collected from effluent sites in Biyagama and Pugoda are given in Table 1. Water appeared blackish blue and brownish yellow in colour in both sampling sites. According to the BOI textile wastewater effluent limits (BOI, 2010), BOD, TSS and nitrate levels were below the given standard limits except for $\mathrm{pH}$ in Biyagama sampling site. However, considerably high EC, phosphate and TDS were recorded both in Pugoda and Biyagama effluent water, although the standards have not been decided for Sri Lanka (Table 1). More or less similar water quality values to those of the current study were recorded by Mahagamage et al. (2015) suggesting that the selected locations were highly contaminated by textile wastewater effluents. In the present study fungal species in such harsh environment were isolated to evaluate their potential impact on decolourisation of CI Direct Blue 201 dye.

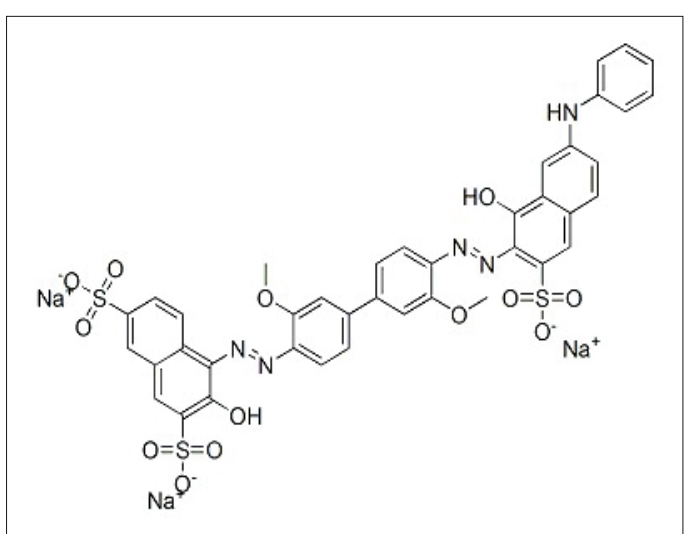

Figure 1: Structure of CI direct Blue 201 textile dye (Source: Chemical Book, 2017)

Isolation and identification of CI Direct Blue 201 textile dye decolourising fungal isolates

A total of 27 pure fungal isolates having different morphological characteristics were isolated from two sampling locations. A total of six isolates (two from Biyagama and four from Pugoda) that showed medium and high decolourising zones on agar plates were selected for further studies. Fungal strains isolated from the Pugoda effluent water and soil showed high textile dye decolourising potentials compared to those of Biyagama (Table 2).

The selected six fungal strains were subjected to liquid medium screening for qualitative analysis of textile dye decolourisation. From those, F 07 and F 09 strains isolated from Pugoda soil samples showed

Table 1: Physiochemical parameters of collected wastewater samples

\begin{tabular}{lccc}
\hline Parameter & Biyagama & Pugoda & $\begin{array}{c}\text { BOI textile waste } \\
\text { water effluent limits }\end{array}$ \\
\hline Temperature $\left({ }^{\circ} \mathrm{C}\right)$ & $29.60 \pm 0.15$ & $31.60 \pm 0.20$ & 40 \\
Conductivity $(\mu \mathrm{S} / \mathrm{cm})$ & $2910 \pm 338.33$ & $4040 \pm 195.02$ & $\mathrm{~N} / \mathrm{S}$ \\
$\mathrm{pH}$ & $8.20 \pm 0.05$ & $7.82 \pm 0.16$ & $6.5-8.0$ \\
$\mathrm{DO}(\mathrm{mg} / \mathrm{L})$ & $2.74 \pm 0.13$ & $1.69 \pm 0.14$ & $\mathrm{~N} / \mathrm{S}$ \\
$\mathrm{BOD}(\mathrm{mg} / \mathrm{L})$ & $11.5 \pm 0.53$ & $15.20 \pm 0.57$ & 60 \\
$\mathrm{Hardness}(\mathrm{mg} / \mathrm{L})$ & $71.67 \pm 0.60$ & $47.67 \pm 0.84$ & $\mathrm{~N} / \mathrm{S}$ \\
$\mathrm{N}^{-\mathrm{NH}}{ }_{4}^{+}(\mathrm{mg} / \mathrm{L})$ & $3.59 \pm 0.37$ & $0.03 \pm 0.06$ & 60 \\
$\mathrm{~N}^{-\mathrm{NO}}{ }_{3}^{-}(\mathrm{mg} / \mathrm{L})$ & $22.02 \pm 0.04$ & $27.57 \pm 1.78$ & $\mathrm{~N} / \mathrm{S}$ \\
$\mathrm{PO}_{4}^{-3}(\mathrm{mg} / \mathrm{L})$ & $149.61 \pm 0.81$ & $332.23 \pm 12.15$ & $\mathrm{~N} / \mathrm{S}$ \\
$\mathrm{TDS}_{(\mathrm{mg} / \mathrm{L})}$ & $1936.67 \pm 24.06$ & $2522.67 \pm 28.48$ & $\mathrm{~N} / \mathrm{S}$ \\
$\mathrm{TSS}(\mathrm{mg} / \mathrm{L})$ & $28.67 \pm 4.1$ & $42.00 \pm 2.30$ & 50 \\
\hline
\end{tabular}

$\mathrm{N} / \mathrm{S}$ : Not stated in BOI textile wastewater effluent limits (BOI, 2010). $\mathrm{n}_{\text {Biyagama }}=3, \mathrm{n}_{\text {Pugoda }}=3$ 
Table 2: Qualitative evaluation of the dye decolourising potential of isolated fungal isolates

\begin{tabular}{llllll}
\hline Ref. no & $\begin{array}{l}\text { Isolated } \\
\text { location }\end{array}$ & Decolourisation & Ref. no & $\begin{array}{l}\text { Isolated } \\
\text { location }\end{array}$ & Decolourisation \\
\hline F 01 & BY/S & Low & F 15 & BY/W & Absent \\
F 02 & BY/S & Absent & F 16 & BY/W & Absent \\
F 03 & BY/S & Absent & F 17 & BY/W & Low \\
F 04 & BY/S & Medium & F 18 & BY/W & Absent \\
F 05 & BY/S & Absent & F 19 & BY/W & Absent \\
F 06 & BY/S & Low & F 20 & BY/W & Medium \\
F 07 & PG/S & High & I 01 & PG/W & Absent \\
F 08 & PG/S & Medium & I 02 & PG/W & Low \\
F 09 & PG/S & High & I 03 & PG/W & Absent \\
F 10 & PG/S & Low & I 04 & PG/W & Low \\
F 11 & PG/S & Low & I 05 & PG/W & Medium \\
F 12 & PG/S & Low & I 06 & PG/W & Absent \\
F 13 & PG/S & Absent & I 07 & PG/W & Low \\
F 14 & BY/W & Absent & & & \\
\hline
\end{tabular}

BY/S: Biyagama-Soil, BY/W: Biyagama-Water, PG/S: Pugoda-Soil, PG/S: Pugoda-Water

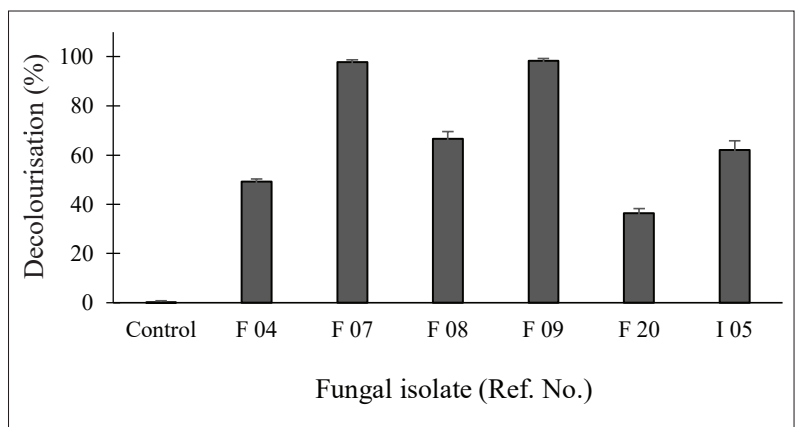

Figure 2: Decolourisation percentages for pre-selected fungal isolates by liquid medium screening (at 72 hours of incubation). When error bars are not shown, the standard deviation was less than the width of the symbol.
$97.76 \pm 1.02 \%$ and $98.32 \pm 0.93 \%$ decolourisation, respectively after 3 days of incubation (Figure 2) demonstrating complete disappearance of colour to the naked eye (Figure 3). These two isolates were identified as Aspergillus nomius (F 07) and Aspergillus aculeatus (F 09) by 18 s rRNA analysis.

Decolourisation of textile dyes by $A$. nomius and $A$. aculeatus is recorded here for the first time although Aspergillus niger and Aspergillus foetidus, species that belong to the same genus have been recorded as positive textile dye decolourising agents for some other dyes $(\mathrm{Fu}$ \& Viharaghavan, 2002). Furthermore, Ekanayake and Manage (2017) have reported the decolourisation ability of some bacterial strains against CI Direct Blue 201 dye.

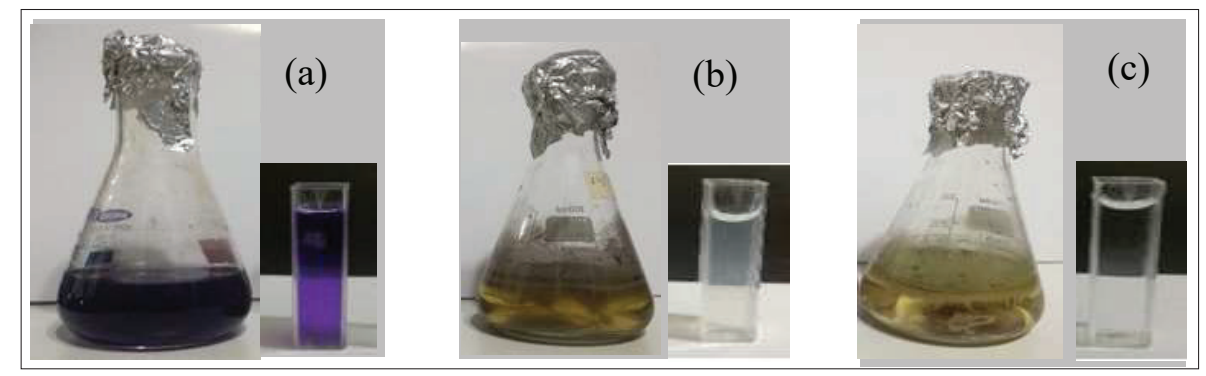

Figure 3: Changes of the colour of CI Direct Blue 201 dye after 72 hours of incubation with A. aculeatus and A. nomius. (a): Control; (b): decolourised product by A. aculeatus; (c): decolourised product by $A$. nomius 
The mechanisms of textile dye decolourisation by biological agents are highly dependent on the structure of the dye, fungal species used, initial dye concentration, incubation time period and nutrient content in the growth medium (Fu \& Viraraghavan, 2002; Plácido et al., 2016). Plácido et al. (2016) recorded the decolourisation of Remazol black dye by Leptosphaerulina sp. through both enzymatic and biosorption processes. Further, Fu and Viraraghavan (2002) reported the decolourisation of Congo red by $A$. niger occurred through biosorption of dyes while Rani et al. (2014) recorded the decolourisation of malachite green dye by the fungus A. niger via extracellular enzyme, absorption and adsorption mechanisms. Thus, the results of the present study showed that the textile dye decolourisation behaviour may vary even in the fungi belonging to the same genus.

Dhanjal et al. (2013) have recorded complete decolourisation of $10 \mathrm{mg} / \mathrm{L}$ Rubine toner 12 dye with $A$. niger within 5 days on PDB medium, while low decolourisation potentials ( $24 \%$ and $1 \%$ ) were reported by Gnanadoss and Jebapriya (2013) in 12 hours on Congo red and Erichrome black $\mathrm{T}$ dye, respectively. Astrazone blue dye decolourisation activity of Funalia trogii was recorded as $92 \%$ within 24 hours (Yesilada et al., 2003). A. nomius and A. aculeatus isolated in the present study showed $98 \%$ decolourisation of $50 \mathrm{mg} / \mathrm{L}$ CI Direct Blue 201 textile dye in 3 days of incubation with a supplement of modified Kirk's medium. Half life time, the time spent to reduce the initial dye concentration by half, was 44 hours and 38 hours for $A$. nomius and A. aculeatus, respectively. Therefore, these two strains can be considered as good candidates to treat CI Direct Blue 201 textile dye as biological agents.

\section{Optimisation of some selected physiochemical parameters for dye decolourisation}

The components and conditions in textile wastewater effluents vary greatly (Tüfekci et al., 2007) and living microorganisms in such aquatic environments must be able to tolerate fluctuation of temperature, $\mathrm{pH}$ and organic substrates etc. (Patel \& Suresh, 2008). Hence, the effect of key physical and chemical parameters in the process of fungal decolourisation of CI Direct Blue 201 textile dye was evaluated in detail.

Temperature is an essential factor for microbial cell viability, growth and enzymatic activities. According to the Sri Lankan textile wastewater guidelines, the temperature in textile effluent water should be less than $40{ }^{\circ} \mathrm{C}$ (BOI, 2010) and the recorded environmental water temperature was around $29.6{ }^{\circ} \mathrm{C}$ to $31.6{ }^{\circ} \mathrm{C}$. Therefore,

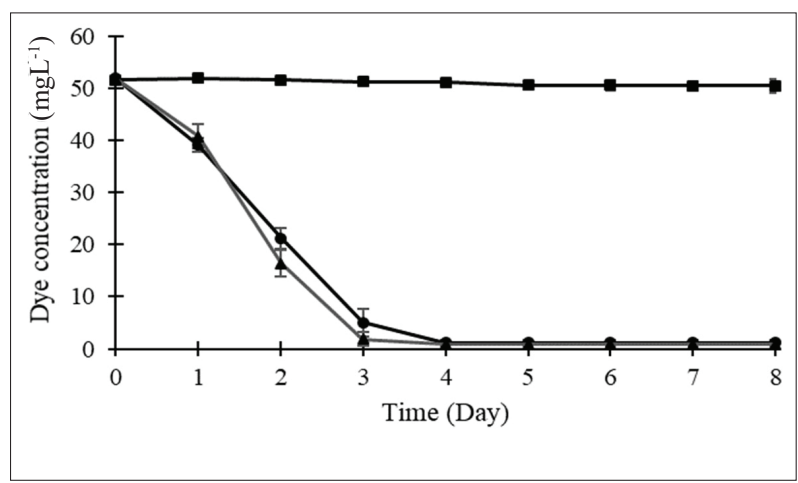

Figure 4: Reduction of the CI Direct Blue 201 dye concentration with fungal treatment.

When error bars are not shown, the standard deviation was less than the width of the symbol. ( $\bullet$ : dye with $A$. nomius, $\boldsymbol{\Delta}$ : dye with $A$. aculeatus, $\mathbf{m}$ : control).

the effect of temperature on dye decolourisation was evaluated in the range of $24{ }^{\circ} \mathrm{C}$ to $36^{\circ} \mathrm{C}$ (Figure 5a). Both $A$. nomius and $A$. aculeatus were found to be equally effective in dye decolourisation at all tested temperatures. Typically, the optimum temperature for fungal growth is between $25^{\circ} \mathrm{C}$ to $35^{\circ} \mathrm{C}$ (Fu \& Viraraghavan, 2002).

Fungal decolourisation appears to depend on the agitation conditions (Yesilada et al., 2003; Przystas et al., 2015). In the present study dye decolourisation effect was studied under static and shaking conditions. The results revealed that the decolourisation percentages were reduced from $97.76 \pm 1.02 \%$ to $24 \pm 1.52 \%$ for $A$. nomius and $98.32 \pm 0.93 \%$ to $33 \pm 1.28 \%$ for $A$. aculeatus, when conditions changed from shaking $(100 \mathrm{rpm})$ to static conditions, respectively (Figure $5 \mathrm{~b}$ ). Thus, the results of the present study indicated that the rapid growth and decolourisation by $A$. nomius and A. aculeatus were favoured by shaking conditions. A similar effect has been recorded by Yesilada et al. (2003) for F. trogii on Astrazone blue dye decolourisation. Przystas et al. (2015) recorded that decolourisation of a mixture of dye was more effective at shaking conditions for a mixed fungal consortium. A. niger, belonging to the same genus as the species in the present study was recorded to prefer static conditions for rapid decolourisation of Malachite green and Nigrosin dyes (Rani et al., 2014). However, Ali et al. (2008) reported that $A$. niger preferred shaking conditions for its rapid growth and decolourisation of Acid red 151 and Sulfer black dyes and concluded that the effect is species dependent. Thus, the effect of agitation conditions on dye decolourisation may depend on the type of textile dye and the fungal species used in the treatment. 
Alkaline and acidic conditions in the textile wastewater is highly dependent on the fabric and type of dye (El-Rahim et al., 2009). Therefore, evaluation of textile dye decolourising ability of the selected fungal strains at different $\mathrm{pH}$ range is essential to achieve an effective bioremediation process. According to the wastewater quality standards in Sri Lanka, the $\mathrm{pH}$ should be within 6.5 to 8.0 range when textile wastewater is released to the environment (BOI, 2010). Therefore, six different $\mathrm{pH}$ values; 5, 6, 7, 8, 9 and 10 were tested for the effectiveness of CI Direct Blue 201 textile dye decolourisation using the two fungal species in the present study (Figure 5c). After three days of incubation at $\mathrm{pH} 7,97.8 \%$ and $98.2 \%$ of decolourisation were obtained by $A$. nomius and $A$. aculeatus, respectively. However, A. nomius and $A$. aculeatus showed $86.54 \pm 2.36 \%$ and $93.29 \pm$
$3.61 \%$ decolourisation within two days of incubation when $\mathrm{pH}$ in the medium was 10 . More or less similar decolourisation percentages were recorded for $\mathrm{pH} 5$ at the same conditions, emphasising that decolourisation was more effective at slightly acidic and basic conditions rather than neutral. El-Rahim et al. (2009) recorded that $\mathrm{pH} 2,3,8$ and 9 were the most effective $\mathrm{pH}$ values for direct dye removal by $A$. niger. However, results of the present study suggested $\mathrm{pH} 5$ and 10 were the most favourable conditions for decolourisation of CI Direct Blue 201 textile dye by both $A$. nomius and $A$. aculeatus, indicating that the decolourisation of textile dyes by fungi is species specific. Results of the present study clearly showed that $A$. nomius and $A$. aculeatus will be potential microorganisms to be used in dye bioremediation processes.

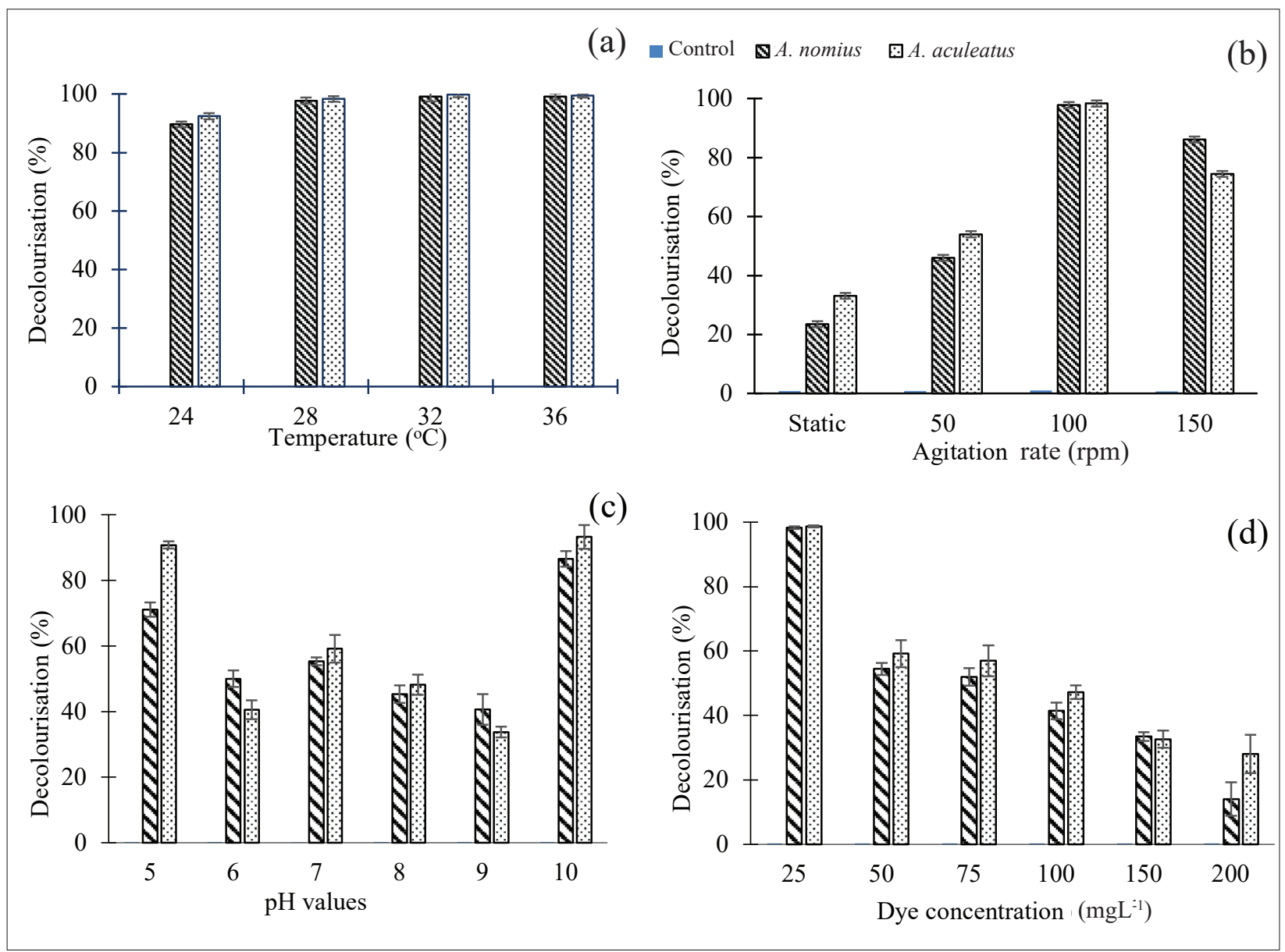

Figure 5: Effect of (a) temperature*; (b) agitation status;; (c) $\mathrm{pH}^{* *}$ and (d) different initial dye concentrations ${ }^{* *}$ on decolourisation percentage by A. nomius and A. aculeatus. When error bars are not shown, the standard deviation was less than the width of the symbol. No control gave more than $2 \%$ decolourisation.

*: at three days of incubation, $* *$ : at two days of incubation 
Textile wastewaters in the range of 10 to $200 \mathrm{mg} / \mathrm{L}$ are extremely coloured and most of the dyes are visible in the water even at concentrations as low as $1 \mathrm{mg} / \mathrm{L}$ (Pandey et al., 2007). Therefore, decolourisation potential by the selected fungi was assessed in the concentration range of 25 to $200 \mathrm{mg} / \mathrm{L}$. According to Figure $5 \mathrm{~d}$, decolourisation was highly dependent on the initial dye concentrations. It was found that both $A$. nomius and A. aculeatus need at least two days for complete decolourisation of $25 \mathrm{mg} / \mathrm{L}$ of initial dye. However, when the initial dye concentration was increased, a descending order of dye decolourisation percentage was found for both fungal species. Similarly, Bankole et al. (2018) recorded that decolourisation of Scarlet RR dye by $P$. prosopidis was decreased as a response to increasing the initial dye concentration. Increasing the concentration of dye may directly influence on the decolourisation potential by fungal species due to their toxic effect.

The present study showed that A. nomius and A. aculeatus did not grow in water without supplement of nutrients. Hence, modified Kirk's medium was selected for liquid medium screening supplemented with different carbon and nitrogen sources. A. aculeatus showed $84.02 \pm 2.34 \%$ and $70.65 \pm 2.69 \%$ decolourisation with ammonium nitrate and glucose supplementation, respectively after two days of incubation (Figure 6).

Moreover, supplement of glucose increased the decolourisation ability of $A$. nomius. Previous studies have suggested that the presence of glucose, starch and maltose like carbon sources enhance the dye removal by different fungal isolates (Miranda et al., 1996). However, in the present study, starch did not play a significant role in fungal dye decolourisation. A. nomius and A. aculeatus showed $61.5 \pm 3.3 \%$ and $84.0 \pm 2.3 \%$ decolourisation of CI Direct Blue 201 dye respectively, with the presence of ammnoium nitate in the medium. However, decolourisation percentages were reduced when the medium was enriched with ammonium chloride (Figure 6). It might be dependent on fungal species used and the type of the dye employed (Vasdev et al., 1995).

The effect of consecutive addition of CI Direct Blue 201 textile dye $(50 \mathrm{mg} / \mathrm{L})$ into the same flask was studied in the present study (Figure 7). A. aculeatus took 72 hours to complete $(\sim 98 \%)$ the $1^{\text {st }}$ decolourisation cycle. At that time, $50 \mathrm{mg} / \mathrm{L}$ of CI Direct Blue 201 textile dye was added to the existing biomass without supplement of further nutrients and decolourisation was observed within 12 hours. Similarly, successive decolourisations were observed up to six cycles each taking 12 hours. The extent of decolourisation decreased progressively in the latter cycles. At the end of the first cycle, A. aculeatus was well established in the Erlenmeyer flask by reaching its maximum surface area on the flask $(5 \pm 0.5 \mathrm{~cm})$. This may have been favourable for rapid decolourisation and reduction of time that was required to complete decolourisation in the following cycles. However, the reduction of dye decolourisation ability of fungi after $6^{\text {th }}$ cycle may be due to the depletion of viable cell count and the the nutrients in the system. Similar

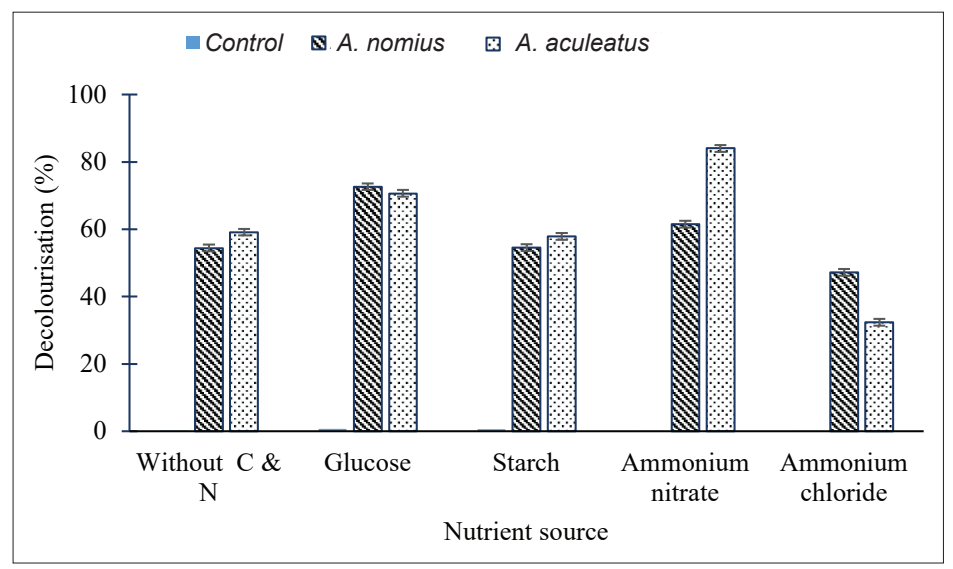

Figure 6: Effect of addition of carbon or nitrogen source on decolourisation percentage of CI Direct Blue 201 textile dye by A. nomius and A. aculeatus after two days of incubation. When error bars are not shown, the standard deviation was less than the width of the symbol. No control gave more than $2 \%$ decolourisation. 


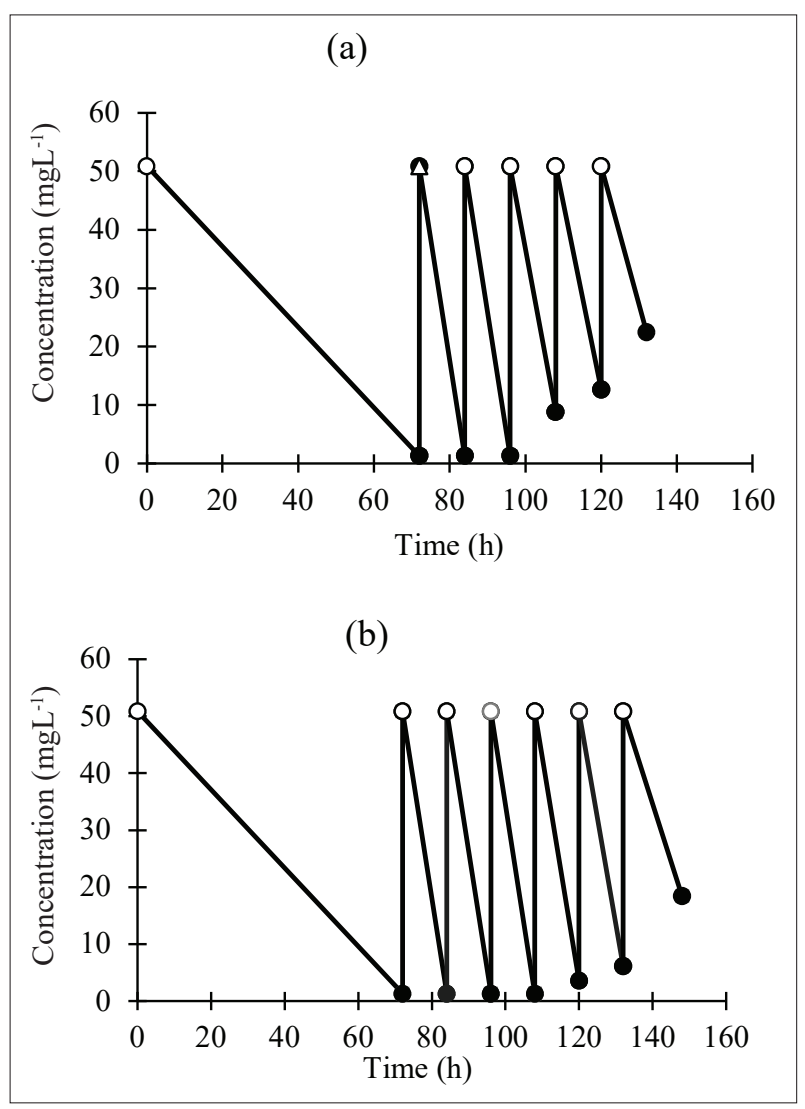

Figure 7: CI Direct Blue 201 dye concentration variation with the repeated dye addition for (a): A. aculeatus and (b): $A$. nomius. $\bigcirc$ : the dye addition points that initiation of a new cycle, $\bullet$ : end point of the decolourisation cycle

patterns were recorded for $A$. nomius and it was found that decolourisation was well effective up to five cycles. It was recorded that decolourisation of Astrazone blue dye by $F$. trogii was successful up to five cycles and then declined sharply (Yesilada et al., 2003). Repeated usability of the same biomass up to several cycles ensures the economically effective applicability of selected fungal strains in biological treatment processes.

\section{Bio-sorption study}

When evaluating the dye decolourisation ability of fiveday-old live and dead fungal isolates, live fungi showed complete decolourisation within 12 hours of incubation. However, when the dye was treated with dead fungal biomass of $A$. nomius and $A$. aculeatus, relatively low percentages of decolourisation $(8.6 \pm 2.12 \%$ and $3.3 \pm 1.19 \%$, respectively) was observed within the same incubation time (Table 3). Przystas et al. (2015) recorded that a mixture of Brilliant green and Evans blue dyes was decolourised only up to $37 \%$ with dead fungal biomass of Pleurotus ostreatus and Polyporus picipes compared to live biomass $(90 \%)$ and suggested that bio-sorption only accounted for a little amount of dye decolourisation. Therefore, the present study suggests that the decolourisation of CI Direct Blue 201 textile dye by two fungal species may possibly be due to biotransformation processes rather than bio-sorption. Thus, studies are being continued to investigate the possible mechanisms of the decolourisation of CI Direct Blue 201 textile dye by A. nomius and A. aculeatus.

\section{Phytotoxicity study}

Coloured textile wastewater effluents pose various environmental threats. Most of these effluents finally end up in natural water bodies. Therefore, it is important to assess the toxicity of the original and the decolourised product of dye to ensure that the treated effluent has been detoxified. The seed germination percentage of $O$. sativa against CI Direct Blue 201 textile dye was $22.2 \pm 5.0 \%$ whereas for $V$. radiata it was $10.0 \pm$ $3.3 \%$. When the seeds were treated with fungal treated dye solutions, $100 \%$ seed germination was recorded indicating that the decolourised by-products were not toxic to seeds. Bankole et al. (2018) also recorded improved germination of Triticum aestivum (monocot) and Phaseolus mungo (dicot), when Scarlet RR dye was treated by $P$. prosopidis. Similar results were recorded by Zhuo et al. (2011) confirming that the toxic nature of textile dyes is removed by some biological agents.

Table 3: Dye decolourisation percentage by live and dead (autoclaved) fungal biomass

\begin{tabular}{llr}
\hline Isolate & & $\begin{array}{c}\text { Decolourisation percentage (\%) } \\
\text { (at 12 hours incubation) }\end{array}$ \\
\hline Control & (Only dye) & $0.26 \pm 0.31$ \\
A. nomius & Live & $97.8 \pm 1.02$ \\
& Dead & $8.6 \pm 2.12$ \\
A. aculeatus & Live & $98.6 \pm 0.46$ \\
& Dead & $3.3 \pm 1.19$
\end{tabular}




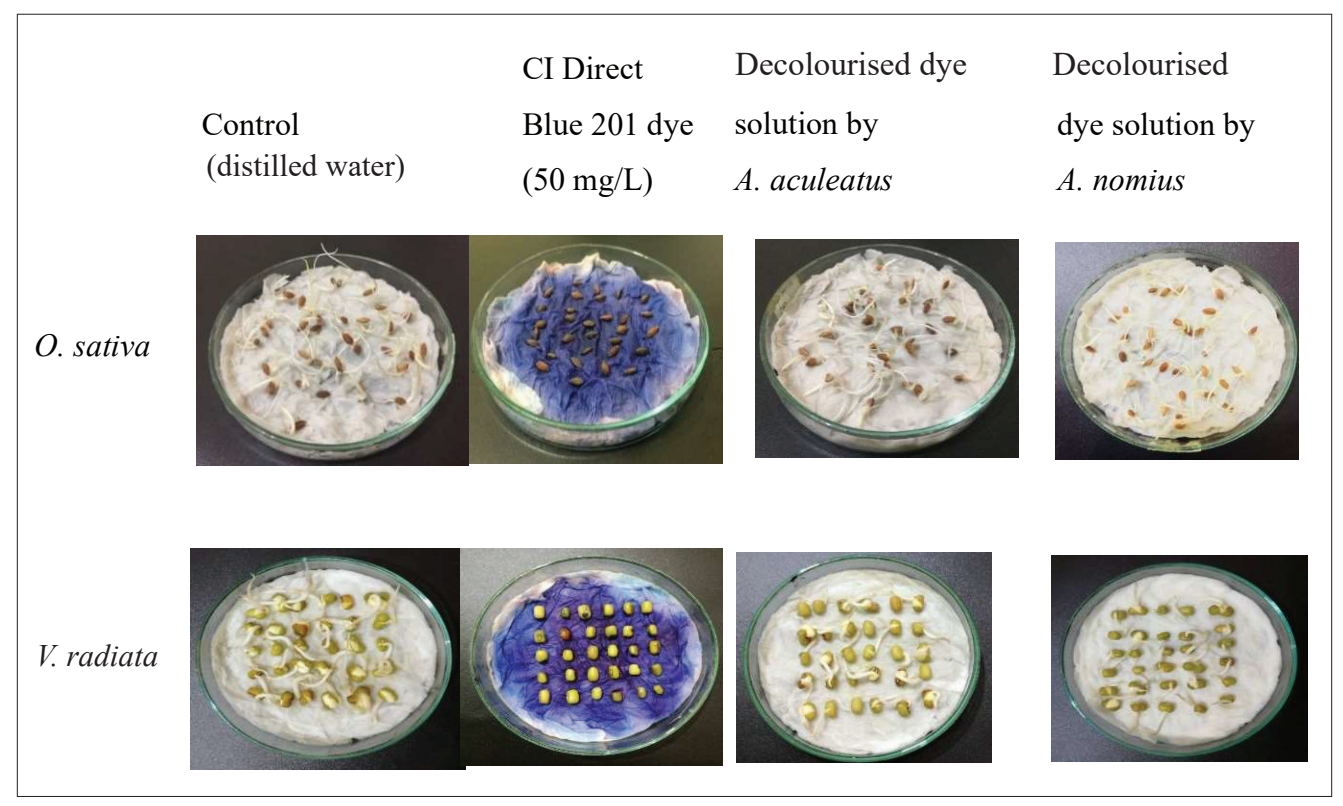

Figure 8: $\quad$ Seed germination of $O$. sativa and $V$. radiata in dye solution and decolourised dye solution

\section{CONCLUSION}

Treatment of textile dyes by fungi has mostly been recorded with white rot fungi. However, in the present study, isolated filamentous fungi $A$. nomius and A. aculeatus belonging to a different group exhibited remarkable decolourisation potential $(97.76 \pm 1.02 \%$ and $98.32 \pm 0.93 \%$, respectively at $100 \mathrm{rpm}, 28{ }^{\circ} \mathrm{C}$ in 72 hours) of CI Direct Blue 201 textile dye which has been studied less under bio-treatment processes. Decolourisation was observed by both fungal strains under a wide range of temperature $\left(24{ }^{\circ} \mathrm{C}\right.$ to $\left.36{ }^{\circ} \mathrm{C}\right)$ and the presence of glucose, ammonium nitrate, $\mathrm{pH}$ 5 and 10 enhanced the decolourisation ability of both fungal species. Phytotoxicity studies confirmed the detoxification of the toxic nature of the dye. Thus, findings of the present study suggest that the isolated $A$. nomius and $A$. aculeatus can be used as potential biological candidates for textile dye decolourisation in future biotechnological applications.

\section{Acknowledgement}

The authors acknowledge the financial support provided by the Research Council, University of Sri Jayewardenepura, Sri Lanka under the research grant no: ASP/01/RE/SCI/2016/10).

\section{REFERENCES}

Ali N., Hameed A., Ahmed S. \& Khan A.G. (2008). Decolourisation of structurally different textile dyes by Aspergillus niger SA1. World Journal of Microbiology and Biotechnology 24(7): 1067-1072.

DOI: https://doi.org/10.1007/s11274-007-9577-2

American Public Health Association (APHA) (1995). APHA Standard Methods, $19^{\text {th }}$ edition. American Public Health Association, Washington DC, USA.

Anandhana M., Prabhahar R.S.S., Thanikachalamc J. \& Arunrajd T. (2018). Evaluation of phycoremediation potentials of microalgae with reference to textile dyeing industrial effluent. International Journal of Applied Engineering Research 13(8): 6440-6445.

Anjana S. \& Thanga V.S.G. (2011). Phytoremediation of synthetic textile dyes. Asian Journal of Microbiology 13(1): 30-39.

Banat I.M., Nigam P., Singh D. \& Marchant R. (1996). Microbial decolourisation of textile-dye containing effluents: a review. Bioresource Technology 58(3): 217-227.

Bankole P.O., Adekunle A.A., Obidi O.F., Chandanshive V.V. \& Govindwar S.P. (2018). Biodegradation and detoxification of Scarlet RR dye by a newly isolated filamentous fungus, Peyronellaea prosopidis. Sustainable Environment Research 28(5): 214-222.

DOI: https://doi.org/10.1016/j.serj.2018.03.001

Board of Investments (BOI) (2010). Textile Wastewater Effluent Guidelines, Environmental Norms; Sri Lanka. Board of Investments. Available at http://www.investsrilanka.com/ 
wp-content/uploads/2018/07/environmental_norms-1.pdf, Accessed November 2016.

Bumpus J.A. (1995). Microbial degradation of azo dyes. Progress in Industrial Microbiology 32: 157-176.

Central Environmental Authority (CEA) (1992). Industrial Pollution Guideline: Textile Processing Industries. Central Environmental Authority, Sri Lanka. Available at http:// dl.nsf.ac.lk/ohs/cea/06222.pdf, Accessed May 2016.

Central Bank of Sri Lanka (2016). Central Bank Annual Report. Available at https://www.cbsl.gov.lk/en/publications/ economic-and-financial-reports/annual-reports/annualreport-2016, Accessed December 2017.

Chemical Book, CI Direct Blue 201, Basic information, Available at https://www.chemicalbook.com/Product ChemicalPropertiesCB01453522_EN.htm, Accessed December 2017

Chen K.C., Wu J.Y., Liou D.J. \& Hwang S.J. (2003). Decolourisation of the textile dyes by newly isolated bacterial strains. Journal of Biotechnology 101: 57-68.

Dhanjal N.I.K., Mittu B., Chauhan A. \& Gupta S. (2013). Biodegradation of textile dyes using fungal isolates. Journal of Environmental Science and Technology 6(2): 99-105. DOI: https://doi.org/10.3923/jest.2013.99.105

Ekanayake E.M.M.S. \& Manage P.M. (2017). Decolourisation of CI Direct Blue 201 textile dye by native bacteria. International Journal of Multidisciplinary Studies 4(1): 49-58.

DOI: https://doi.org/10.4038/ijms.v4i1.36

El-Rahim W.M.A., El-Ardy O.A.M. \& Mohammad F.H. (2009). The effect of $\mathrm{pH}$ on bioremediation potential for the removal of direct violet textile dye by Aspergillus niger. Desalination 249(3): 1206-1211.

DOI: https://doi.org/10.1016/j.desal.2009.06.037

$\mathrm{Fu}$ Y. \& Viraraghavan T. (2002). Dye biosorption sites in Aspergillus niger. Bioresource Technology 82(2): 139-145.

Gnanadoss J.J. \& Jebapriya G.R. (2013). Decolourization of synthetic dyes using free and immobilized Aspergillus species. Research in Biotechnology 4(5): 20-23.

Gupta N., Kushwaha A.K. \& Chattopadhyaya M.C. (2016). Application of potato (Solanum tuberosum) plant wastes for the removal of methylene blue and malachite green dye from aqueous solution. Arabian Journal of Chemistry 9(1): 707-716.

DOI: https://doi.org/10.1016/j.arabjc.2011.07.021

Ileperuma O.A. (2000). Environmental pollution in Sri Lanka: a review. Journal of the National Science Foundation of Sri Lanka 28(4): 301-325.

DOI: https://doi.org/10.4038/jnsfsr.v28i4.2644

Jin X.C., Liu G.Q., Xu Z.H. \& Tao W.Y. (2007). Decolourisation of a dye industry effluent by Aspergillus fumigatus XC6. Applied Microbiology and Biotechnology 74(1): 239-243.

DOI: https://doi.org/10.1007/s00253-006-0658-1

Kabbout R. \& Taha S. (2014). Biodecolourisation of textile dye effluent by biosorption on fungal biomass materials. Physics Procedia 55: 437-444.

DOI: https://doi.org/10.1016/j.phpro.2014.07.063

Kalyani D.C., Patil P.S., Jadhav J.P. \& Govindwar S.P. (2008).
Biodegradation of reactive textile dye Red BLI by an isolated bacterium Pseudomonas sp. SUK1. Bioresource Technology 99(11): 4635-4641.

DOI: https://doi.org/10.1016/j.biortech.2007.06.058

Kulla H.G., Klausener F., Meyer U., Lüdeke B. \& Leisinger T. (1983). Interference of aromatic sulfo groups in the microbial degradation of the azo dyes Orange I and Orange II. Archives of Microbiology 135(1): 1-7.

DOI: https://doi.org/10.1007/BF00419473

Mahagamage M.G.Y.L. \& Manage P.M. (2015). Water quality index (CCME-WQI) based assessment study of water quality in Kelani river basin, Sri Lanka. The $1^{\text {st }}$ Environment and Natural Resources International Conference, Bangkok, Thailand, pp. 199-204.

Mahagamage M.G.Y.L., Chinthaka S.D.M. \& Manage P.M. (2015). Multivariate analysis of physico-chemical and microbial parameters of surface water in Kelani river basin. International Journal of Multidisciplinary Studies 1(1): 55-61.

DOI: https://doi.org/10.4038/ijms.v1i1.37

Miranda M.P., Benito G.G., Cristibal N.S. \& Nieto C.H. (1996). Colour elimination from molasses wastewater by Aspergillus niger. Bioresources Technology 57(3): 229-235.

Morais L.C., freitas O.M., Goncalves E.P., Vasconcelos L.T. \& Gonzaâ Lez Beca C.G. (1999). Reactive dyes removal from wastewaters by adsorption on eucalyptus bark: variables that define the process. Water Research 33(4): 979-988.

Pandey A., Singh P. \& Iyengar L. (2007). Bacterial decolourisation and degradation of azo dyes. International Biodeterioration and Biodegradation 59(2): 73-84.

DOI: https://doi.org/10.1016/j.ibiod.2006.08.006

Patel R. \& Suresh S. (2008). Kinetic and equilibrium studies on the biosorption of reactive black 5 dye by Aspergillus foetidus. Bioresource Technology 99(1): 51-58. DOI: https://doi.org/10.1016/j.biortech.2006.12.003

Plácido J., Chanagá X., Ortiz-Monsalve S., Yepes M. \& Mora A. (2016). Degradation and detoxification of synthetic dyes and textile industry effluents by newly isolated Leptosphaerulina sp. from Colombia. Bioresources and Bioprocessing 3(1): 6.

DOI: https://doi.org/10.1186/s40643-016-0084-x

Przystas W., Zablocka-Godlewska E. \& Grabinska-Sota E. (2015). Efficacy of fungal decolourisation of a mixture of dyes belonging to different classes. Brazilian Journal of Microbiology 46(2): 415-424.

DOI: https://doi.org/10.1590/S1517-838246246220140167

Rani B., Kumar V., Singh J., Bisht S., Teotia P., Sharma S. \& Kela R. (2014). Bioremediation of dyes by fungi isolated from contaminated dye effluent sites for bio-usability. Brazilian Journal of Microbiology 45(3): 1055-1063.

DOI: https://doi.org/10.1590/S1517-83822014000300039

Robinson T., McMullan G., Marchant R. \& Nigam P. (2001). Remediation of dyes in textile effluent: a critical review on current treatment technologies with a proposed alternative. Bioresource Biotechnology 77(3): 247-255.

Roussy J., Chastellan P., Vooren M. \& Guiball E. (2005). Treatment of ink-containing wastewater by coagulation/ flocculation using Biopolymers. Water SA 31(3): 369-376. 
Tüfekci N., Sivri N. \& Toroz İ. (2007). Pollutants of textile industry wastewater and assessment of its discharge limits by water quality standards. Turkish Journal of Fisheries and Aquatic Sciences 7(2): 97-103.

Vasdev K., Kuhad R.C. \& Saxena R.K. (1995). Decolourisation of triphenylmethane dyes by the bird's nest fungus Cyathus bulleri. Current Microbiology 30(5): 269-272.

DOI: https://doi.org/10.1007/BF00295500
Yesilada O., Asma D. \& Cing S. (2003). Decolourisation of textile dyes by fungal pellets. Process Biochemistry 38(6): 933-938.

Zhuo R., Ma L. \& Fan F. (2011). Decolourisation of different dyes by a newly isolated white-rot fungi strain Ganoderma sp. Journal of Hazard Materials 192: 855- 873.

DOI: https://doi.org/10.1016/j.jhazmat.2011.05.106 